\title{
Using "small" molecules to facilitate exchange of bicarbonate and chloride anions across liposomal membranes.
}

\author{
Jeffery T. Davis, ${ }^{1}$ Philip A. Gale, ${ }^{2}$ Oluyomi A. Okunola, ${ }^{1}$ Pilar Prados, ${ }^{3}$ \\ Jose Carlos Iglesias-Sánchez, ${ }^{3}$ Tomás Torroba, ${ }^{4}$ and Roberto Quesada ${ }^{4}$
}

'Department of Chemistry and Biochemistry, University of Maryland, College Park, MD 20742, USA. ${ }^{2}$ School of Chemistry, University of Southampton, Southampton, SO1 7 1BJ, United Kingdom. 3Departamento de Química Orgánica, Universidad Autónoma de Madrid, 28049 Madrid, Spain. ${ }^{4}$ Departamento de Química, Universidad de Burgos, 09001 Burgos, Spain. Correspondence should be addressed to J.T.D. (jdavis@umd.edu),P.A.G. (philip.gale@soton.ac.uk)or R.Q. (rquesada@ubu.es)

Please cite this paper as:

Nature, 2009, 1, pp 138-144

The publisher's version of this paper is available here:

http://www.nature.com/nchem/journal/v1/n2/abs/nchem.178.html

Related articles by Prof Philip A. Gale can be found below:

N. Busschaert and P.A. Gale, (2013) "Small molecule lipid bilayer anion transporters for biological applications" Angew. Chem. Int. Ed. 2013, 52, 1374-1382; DOI: 10.1002/anie.201207535

S.J. Moore, C.J.E. Haynes, J. González, J.L. Sutton, S.J. Brooks, M.E. Light, J. Herniman, G. J. Langley, Vanessa Soto-Cerrato, R. Pérez-Tomás, I. Marques, P.J. Costa, V. Félix and P.A. Gale, (2013) "Chloride, carboxylate and carbonate transport by ortho-phenylene diamine-based bisureas." Chem. Sci. , 4, 103-117; DOI:10.1039/C2SC21112B.

N. Busschaert, I.L. Kirby, S. Young, S.J. Coles, P.N. Horton, M.E. Light and P.A. Gale, (2012) "Squaramides as Potent Transmembrane Anion Transporters." Angew. Chem. Int. Ed., 51, 44264430; DOI: 10.1002/anie.201200729

N. Busschaert, M. Wenzel, M.E. Light, P. Iglesias-Hernández, R. Pérez-Tomás and P.A. Gale, (2011) "Structure-activity relationships in tripodal anion transporters: the effect of fluorination" J. Am. Chem. Soc., 133, 14136-14148; DOI: 10.1021/ja205884y.

P.A. Gale, (2011) "From anion receptors to transporters", Acc. Chem. Res., 44, 216-226; DOI: 10.1021/ar100134p.

N.J. Andrews, C.J.E. Haynes, M.E. Light, S.J. Moore, C.C. Tong, J.T. Davis, W.A. Harrell Jr. and P.A. Gale, (2011) "Structurally simple lipid bilayer transport agents for chloride and bicarbonate", Chem. Sci., 2, 256-260; DOI:10.1039/COSC00503G. 


\section{Using "small" molecules to facilitate exchange of bicarbonate and chloride anions across liposomal membranes.}

Jeffery T. Davis, ${ }^{1}$ Philip A. Gale, ${ }^{2}$ Oluyomi A. Okunola, ${ }^{1}$ Pilar Prados, ${ }^{3}$ Jose Carlos Iglesias-Sánchez, ${ }^{3}$ Tomás Torroba, ${ }^{4}$ and Roberto Quesada ${ }^{4}$

${ }^{1}$ Department of Chemistry and Biochemistry, University of Maryland, College Park, MD 20742, USA. ${ }^{2}$ School of Chemistry, University of Southampton, Southampton, SO17 1BJ, United Kingdom. ${ }^{3}$ Departamento de Química Orgánica, Universidad Autónoma de Madrid, 28049 Madrid, Spain. ${ }^{4}$ Departamento de Química, Universidad de Burgos, 09001 Burgos, Spain. Correspondence should be addressed to J.T.D. (jdavis@umd.edu), P.A.G. (philip.gale@ soton.ac.uk) or R.Q. (rquesada@ubu.es)

Bicarbonate is involved in a variety of biological processes including respiration, regulation of intracellular $\mathrm{pH}$ and fertilization. In this study we show that both simple synthetic anion receptors and the natural product prodigiosin are capable of facilitating chloride/bicarbonate exchange (antiport) across liposomal membranes. While it is well known that proteins regulate $\mathrm{Cl}^{-} / \mathrm{HCO}_{3}{ }^{-}$exchange in cells, our results suggest that small molecules may also be able to regulate the concentration of these anionic species in biological systems. We also describe new NMR assays that were developed for monitoring transmembrane transport of $\mathrm{H}^{13} \mathrm{CO}_{3}^{-}$.

Bicarbonate is an anion of paramount importance in living systems. It is a substrate in photosynthesis, ${ }^{1}$ a component of the buffering system to regulate intra- and extracellular $\mathrm{pH}$ levels, ${ }^{2}$ is generated during cellular respiration from $\mathrm{CO}_{2},{ }^{3}$ and acts as a cellular signal that activates sperm for fertilization. ${ }^{4}$ Indeed, under physiological conditions most dissolved inorganic carbon exits as $\mathrm{HCO}_{3}^{-}$. Bicarbonate cannot diffuse freely across cell membranes and facilitated bicarbonate transport is promoted by membrane bound proteins that function mainly through $\mathrm{Na}^{+} / \mathrm{HCO}_{3}{ }^{-}$co-transport or $\mathrm{Cl}^{-} / \mathrm{HCO}_{3}{ }^{-}$exchange mechanisms. ${ }^{5}$ Dysregulation of bicarbonate transport can lead to conditions such as cystic fibrosis, heart disease and infertility. ${ }^{6-8}$ The lack of structural data for these proteins means that little is known regarding the anion binding sites that modulate their affinity and selectivity. ${ }^{7,8}$ Despite the obvious importance of 
transmembrane bicarbonate transport, there have been no reports, to the best of our knowledge, of "small" molecules that are capable of promoting bicarbonate transport across lipid membranes, in contradistinction to the growing body of work on chloride and $\mathrm{HCl}$ transport across phospholipid vesicle membranes. ${ }^{9-15}$ Phospholipid vesicles have been extensively investigated because of their usefulness as models for biological membranes. Unilamellar vesicles of a specific size are easily produced with control of the entrapped solution. These liposomes can be suspended in an external medium of different composition and release of the encapsulated substrates or influx of substances from the external milieu to the interior of the vesicles, as facilitated by some molecular transporter, can be readily monitored by using fluorescence, NMR or ion selective electrode techniques. Below, we describe studies that demonstrate, for the first time, that synthetic compounds and natural products are able to facilitate transmembrane transport of bicarbonate anion across liposomal membranes.
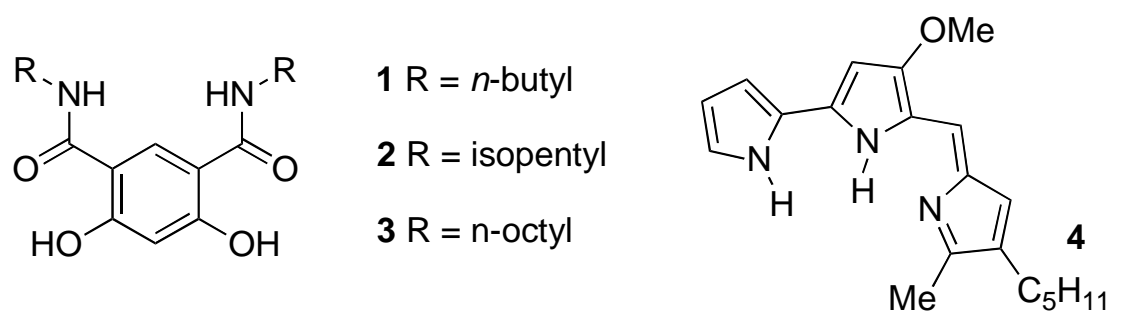

Chart 1. 4,6-Dihydroxyisophthalamides 1-3 and prodigiosin 4.

We recently reported the transmembrane chloride transport activity of 4,6dihydroxyisophthalamide 1. ${ }^{16}$ Isophthalamides have amide $\mathrm{NH}$ groups that are able to form hydrogen bonds with anions. ${ }^{17}$ In the case of $\mathbf{1}$, conformational control of the anion binding cleft by means of intramolecular hydrogen bonds between the 4,6 dihydroxy units and the neighbouring amide carbonyls resulted in an improved anion affinity in solution and in optimal activity for transmembrane transport of chloride anion. For this present study, we also synthesized the closely related isophthalamides $\mathbf{2}$ and $\mathbf{3}$, functionalized with different alkyl substituents on the amide groups (Chart 1). We hypothesized that the bidentate isophthalamide unit might also be effective at binding and, more importantly, transporting trigonal planar oxoanions, such as bicarbonate across lipid membranes.

In addition to synthetic compounds 1-3 we also report below on the bicarbonate transport activity of prodigiosin $4^{18}$, a natural product produced by microorganisms such as Streptomyces and Serratia. ${ }^{19,20}$ This tripyrrolic metabolite has been found to have potent inmunosuppresive and anticancer activities. Prodigiosin appears to cause apoptosis of cancer cells selectively, ${ }^{21}$ and the structural analogue obatoclax is currently in clinical trials for the treatment of cancer. ${ }^{22}$ The origin of the biological activity has yet to be unambiguously established, although there is evidence that this class of compound facilitates the co-transport of $\mathrm{HCl}^{23-28}$ and/or the anion exchange of chloride ${ }^{29,30}$ across lipid bilayer membranes. Indeed, the antibiotic 
activity of prodigiosin-like molecules has been related to their activity as transmembrane $\mathrm{Cl}^{-}$carriers. ${ }^{28}$ As for isophthalamides 1-3, the structure of prodigiosin 4, with its three convergent pyrrole units, seemed to be well suited for coordinating to a trigonal planar anion such as bicarbonate.

We decided to investigate whether these potent chloride transporters (1-4) could also facilitate the transmembrane transport of the bicarbonate anion. In this work, we report 1) the first examples of transmembrane chloride/bicarbonate exchange facilitated by "small" molecules and 2) new NMR methods to monitor the transport of bicarbonate into lipid vesicles. We believe that these studies will set the stage for further development of highly-selective synthetic transporters for bicarbonate anion and perhaps, in the longer term, lead to new approaches for treating diseases caused by defective bicarbonate transport.

\section{RESULTS}

Initially, we wished to compare the chloride transport ability of synthetic receptors 1-3 vs. prodigiosin 4. The transmembrane anion transport abilities of compounds 1-4 were first evaluated by monitoring chloride efflux from unilamellar POPC (1-palmitolyl-2-oleosyl-sn-glycero-3-phosphocholine) vesicles using a chloride selective electrode. ${ }^{31}$ Initial studies were conducted using nitrate in the extravesicular solution. Nitrate is more hydrophobic than bicarbonate and is frequently used in experiments to assess chloride transport efficiency. The liposomes were loaded with a sodium chloride solution and suspended in a sodium nitrate solution. The carrier molecules, dissolved in a small amount $(10 \mu \mathrm{L})$ of DMSO, were then added to the extravesicular solution and the chloride efflux was monitored over $300 \mathrm{~s}$. At the end of the experiment the vesicles were lysed by the addition of detergent and the final value was normalized to equal complete chloride efflux. Isophthalamides 1-3 proved to be potent chloride transporters using this assay (Figure 1a). Carrier loadings as low as $0.1 \%$ molar carrier to lipid were capable of almost complete chloride efflux within $300 \mathrm{~s}$, with the isopentyl-substituted isophthalamide 2 being the most active synthetic transporter under these conditions. A $0.005 \%$ molar carrier to lipid concentration of the natural product prodigiosin 4 showed similar activity to the $0.1 \%$ molar carrier to lipid concentration of the synthetic systems (Figure 1). 
(a)
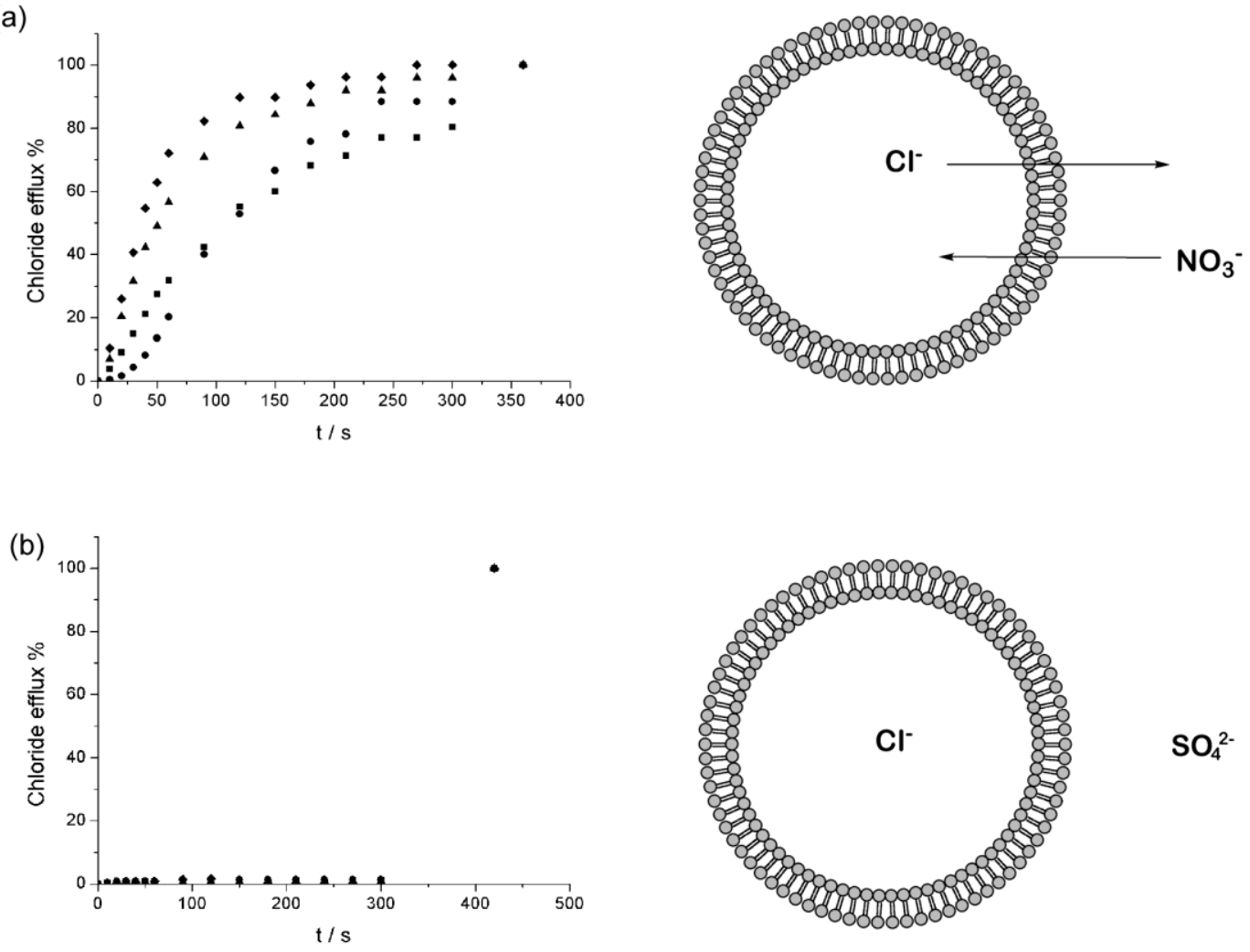

Figure 1. (a) Chloride efflux promoted upon addition of $\mathbf{1}(\mathbf{\bullet}), \mathbf{2}(\mathbf{\Delta}), \mathbf{3}(\bullet)(0.1 \%$ molar carrier to lipid) and $\mathbf{4}(\boldsymbol{})(0.005 \%$ molar carrier to lipid) to unilamellar POPC vesicles loaded with $488 \mathrm{mM} \mathrm{NaCl} 5 \mathrm{mM}$ phosphate buffer $\mathrm{pH} 7.2$ dispersed in 488 $\mathrm{mM} \mathrm{NaNO}_{3} 5 \mathrm{mM}$ phosphate buffer $\mathrm{pH}$ 7.2. At $\mathrm{t}=300 \mathrm{~s}$ the vesicles were lysed by addition of detergent and the final reading at $\mathrm{t}=420 \mathrm{~s}$ was considered to equal $100 \%$ chloride efflux. (b) Chloride efflux studies upon addition of compounds 1-3 $(0.5 \%$ molar carrier to lipid) and $\mathbf{4}(0.04 \%$ molar carrier to lipid) to vesicles composed of POPC. The vesicles contained $\mathrm{NaCl}(488 \mathrm{mM})$ and were immersed in $\mathrm{Na}_{2} \mathrm{SO}_{4}(166$ $\mathrm{mM}$ ), pH 7.2 solution; at $300 \mathrm{~s}$ the vesicles were lysed to obtain $100 \%$ chloride efflux.

In the assay depicted in Figure 1a, the anion transport activity can occur either via $\mathrm{H}^{+} / \mathrm{Cl}^{-}$co-transport or by a $\mathrm{Cl}^{-} / \mathrm{NO}_{3}{ }^{-}$exchange mechanism. To distinguish between these alternative mechanisms, we carried out the $\mathrm{Cl}^{-}$electrode transport assay while varying the anion present in the external medium. If the transport activity is the result of an anion exchange mechanism changing the external anion should impact the transport rate, whilst a $\mathrm{H}^{+} / \mathrm{Cl}^{-}$co-transport mechanism should not be strongly affected by the identity of the external anion to any significant degree. As depicted in Figure $1 \mathrm{~b}$, sulfate was used as an external anion and the transport assay was repeated by suspending the chloride-loaded vesicles in a sulfate containing external medium. As the sulfate dianion carries a higher charge and is significantly more hydrophilic than the nitrate anion, transport activity by compounds $\mathbf{1 - 4}$ should be greatly reduced if an anion exchange mechanism is operative. Indeed, under these conditions, with sulfate as the external anion, no chloride efflux from the liposomes was detected upon addition of 1-4, strongly supporting a chloride/nitrate exchange (antiport) mechanism for mediating anion transport across the vesicle bilayer and additionally 
demonstrating that the carriers do not release chloride by simply disrupting the lipid bilayer.

While both nitrate and bicarbonate have similar sizes and shapes, bicarbonate is significantly more hydrated than nitrate and one might expect that it would be significantly more challenging to transport bicarbonate than nitrate across a non-polar lipid bilayer. ${ }^{32,33}$ Prompted by the $\mathrm{Cl}^{-} / \mathrm{NO}_{3}{ }^{-}$anion exchange activity shown by $\mathbf{1 - 4}$, we designed an experiment to determine whether these compounds could also facilitate bicarbonate/chloride exchange across phospholipid barriers. Chloride loaded vesicles were suspended in a sulfate containing medium. After two minutes, a solution of bicarbonate was added and chloride efflux was monitored over an additional five minutes. At the end of the experiment the vesicles were lysed to calibrate the experimental data to $100 \%$ chloride release. The results shown in Figure 2 confirmed that, as shown above in Figure 1a, negligible chloride efflux was detected in the presence of sulfate as the external anion. Addition of bicarbonate to the extravesicular solution switched on the chloride efflux promoted by 1-4, indicating that these compounds enable chloride/bicarbonate antiport across liposomal membranes. The rate of chloride efflux was dependent on the amount of carrier added to the experiment (see supplementary information Figures S9-S12).
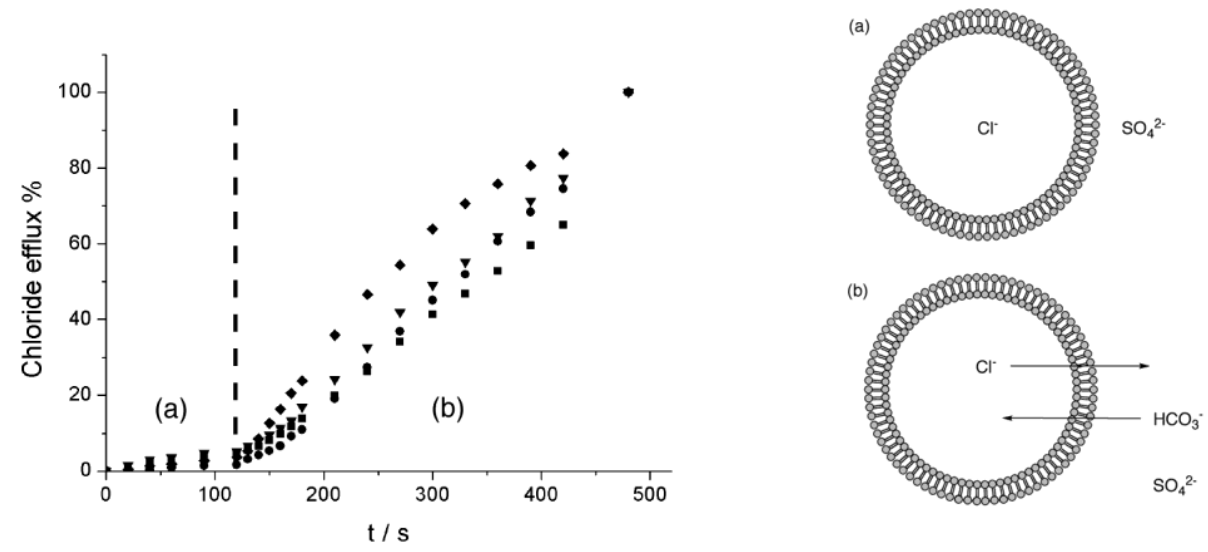

Figure 2. Chloride efflux promoted upon addition of $\mathbf{1}(\boldsymbol{\bullet}), \mathbf{2}(\mathbf{\Delta}), \mathbf{3}(\bullet)$ (1\% molar carrier to lipid) and $\mathbf{4}(\diamond)(0.04 \%$ molar carrier to lipid) to unilamellar POPC vesicles loaded with $451 \mathrm{mM} \mathrm{NaCl} 20 \mathrm{mM}$ phosphate buffer $\mathrm{pH} 7.2$ dispersed in $150 \mathrm{mM}$ $\mathrm{Na}_{2} \mathrm{SO}_{4} 20 \mathrm{mM}$ phosphate buffer $\mathrm{pH}$ 7.2. At $\mathrm{t}=120 \mathrm{~s}$ a solution of $\mathrm{NaHCO}_{3}$ was added to give a $40 \mathrm{mM}$ external concentration. At $\mathrm{t}=420 \mathrm{~s}$ the vesicles were lysed by addition of detergent and the final reading at $t=540 \mathrm{~s}$ was considered to equal $100 \%$ chloride efflux. (a) In the presence of the carrier compounds 1-4 chloride was not released from the vesicles when suspended in a sulfate solution. (b) Upon introduction of bicarbonate to the solution, chloride efflux began as one component of the chloride/bicarbonate antiport mechanism. 
Under the assay conditions addition of bicarbonate induced small changes ( $\sim 0.2$ units) in the $\mathrm{pH}$ of the external medium. We therefore carried out control experiments in the presence of compounds 1-4 to rule out the possibility that chloride efflux was driven by a $\mathrm{pH}$ gradient. Indeed, addition of $\mathrm{NaOH}$ to the external medium resulted in no significant chloride efflux. Furthermore, addition of bicarbonate solutions to a suspension of vesicles without the presence of transporters 1-4 resulted in no chloride efflux.

We used ${ }^{13} \mathrm{C}$ NMR spectroscopy to verify that transporters $\mathbf{1 - 4}$ facilitate transmembrane $\mathrm{HCO}_{3}{ }^{-} / \mathrm{Cl}^{-}$anion exchange across phospholipid vesicles. We developed experiments that use paramagnetic $\mathrm{Mn}^{2+}$ to bleach the ${ }^{13} \mathrm{C}$ NMR signal for extravesicular $\mathrm{H}^{13} \mathrm{CO}_{3}^{-}$, allowing for ready discrimination of extravesicular and intravesicular $\mathrm{H}^{13} \mathrm{CO}_{3}^{-}$. We based these paramagnetic NMR protocols on previous experiments that 1) monitored transmembrane chloride transport in liposomes by ${ }^{35} \mathrm{Cl}$ NMR, ${ }^{34,35}$ and 2) showed that intracellular and extracellular $\mathrm{H}^{13} \mathrm{CO}_{3}{ }^{-}$could be distinguished in plant cells. ${ }^{36,37}$ Our results show that both synthetic $\mathbf{3}$ and natural product 4, facilitate $\mathrm{HCO}_{3}{ }^{-} / \mathrm{Cl}^{-}$exchange across phospholipid membranes. Figure 3 shows data from the first set of NMR experiments conducted to illustrate transportermediated $\mathrm{HCO}_{3}{ }^{-} / \mathrm{Cl}^{-}$exchange. This set of NMR experiments was done under similar conditions as described for the $\mathrm{Cl}^{-}$electrode experiments depicted in Figure 1. Thus, EYPC liposomes $(5 \mu \mathrm{m})$ filled with $450 \mathrm{mM} \mathrm{NaCl}$ were suspended in a sulfate solution and $50 \mathrm{mM} \mathrm{H}^{13} \mathrm{CO}_{3}{ }^{-}$was added to the NMR sample. A sharp ${ }^{13} \mathrm{C} \mathrm{NMR} \mathrm{signal}$ for extravesicular $\mathrm{H}^{13} \mathrm{CO}_{3}{ }^{-}$was observed at $\delta 161 \mathrm{ppm}$. Upon addition of $0.5 \mathrm{mM}$ $\mathrm{Mn}^{2+}$, this signal was broadened into the baseline as the paramagnetic cation interacted with the extravesicular bicarbonate. After addition of transporters (isophthalamide 3 in Figure $3 \mathrm{a}$ and prodigiosin 4 in Figure $3 \mathrm{~b}$ ), a sharp ${ }^{13} \mathrm{C}$ NMR signal for $\mathrm{H}^{13} \mathrm{CO}_{3}{ }^{-}(\delta \sim 161 \mathrm{ppm})$ was restored. This renewed ${ }^{13} \mathrm{C}$ NMR signal must be caused by ligand-mediated transport of $\mathrm{HCO}_{3}{ }^{-}$into the liposome since the paramagnetic $\mathrm{Mn}^{2+}$ is impermeable to the phospholipid bilayer. Importantly, the control experiment in which DMSO was added without transporter, did not result in any restoration of ${ }^{13} \mathrm{C}$ NMR signal (Figure 3c). 

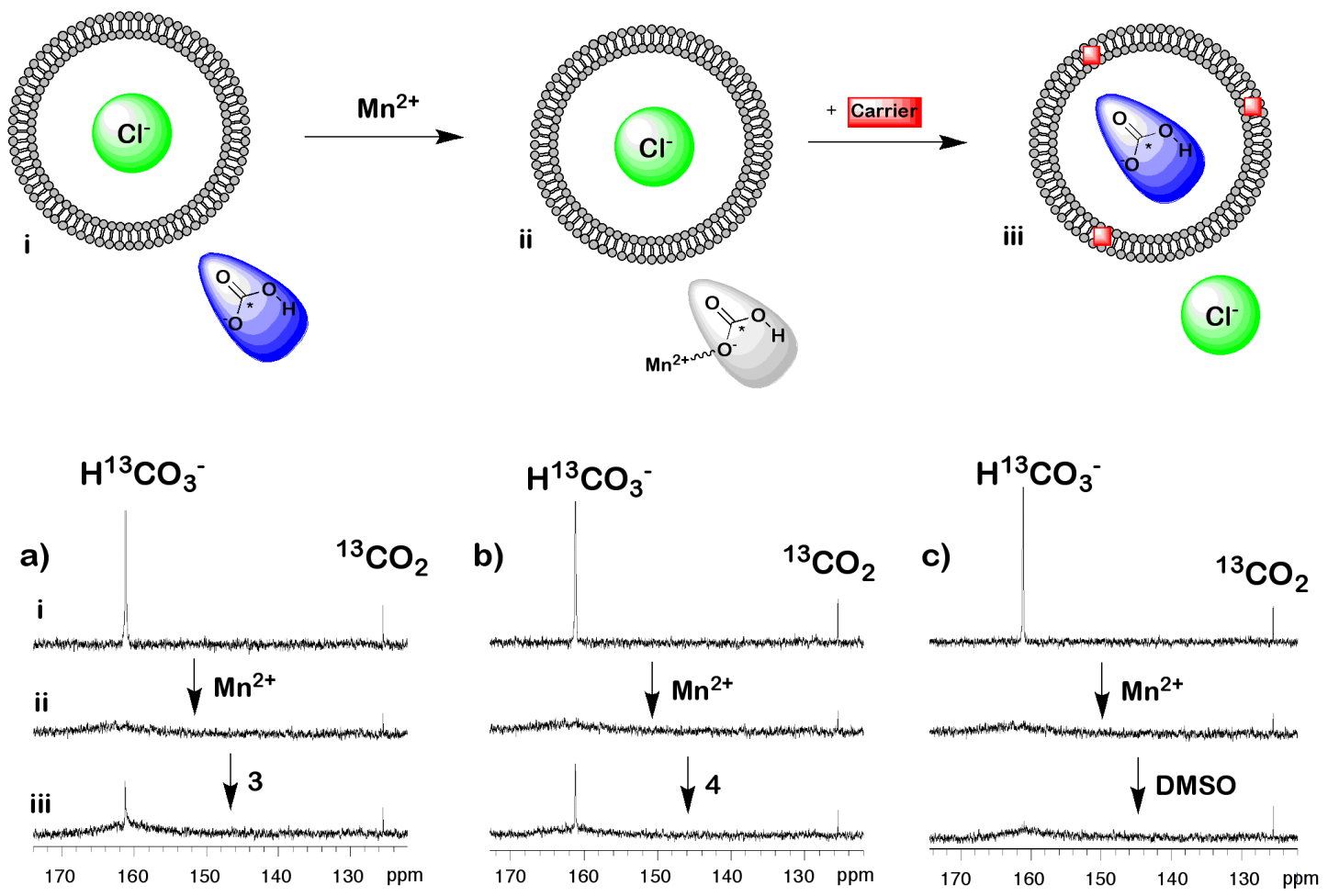

Figure 3. Representation of titration sequence and ${ }^{13} \mathrm{C}$ NMR data (a-c) for monitoring transmembrane transport of $\mathrm{HCO}_{3}{ }^{-}$into $\mathrm{Cl}^{-}$-loaded EYPC liposomes by 3 and $\mathbf{4}$ : i) a $\mathrm{NaH}^{13} \mathrm{CO}_{3}$ pulse $(50 \mathrm{mM})$ was added to EYPC vesicles loaded with $450 \mathrm{mM} \mathrm{NaCl}$, $20 \mathrm{mM}$ HEPES (pH 7.3) and dispersed in $150 \mathrm{mM} \mathrm{Na}_{2} \mathrm{SO}_{4}, 20 \mathrm{mM}$ HEPES (pH 7.3); ii) NMR spectra after addition of $0.5 \mathrm{mM} \mathrm{Mn}{ }^{2+}\left(1: 100 \mathrm{Mn}^{2+} / \mathrm{H}^{13} \mathrm{CO}_{3}{ }^{-}\right.$ratio); iii) $\mathrm{NMR}$ spectra after addition of transporter or DMSO $(3-1 \mathrm{~mol} \%$ relative to lipid, $4-0.1$ mol \%, or DMSO - $403 \mathrm{~mol} \%$ ).

Figure 4 shows data from another NMR experiment designed to verify transportermediated $\mathrm{HCO}_{3}{ }^{-} / \mathrm{Cl}^{-}$exchange. In these experiments we monitored bicarbonate efflux from vesicles loaded with $\mathrm{H}^{13} \mathrm{CO}_{3}{ }^{-}$upon addition of transporters 3 or 4 . Thus, EYPC vesicles filled with $\mathrm{H}^{13} \mathrm{CO}_{3}{ }^{-}$and suspended in $\mathrm{Na}_{2} \mathrm{SO}_{4}$ solution were aged overnight at $4^{\circ} \mathrm{C}$. Two ${ }^{13} \mathrm{C}$ NMR signals separated by $1 \mathrm{ppm}(\delta \sim 162$ and $\sim 161 \mathrm{ppm})$ were observed, corresponding to separate signals for intravesicular and extravesicular $\mathrm{H}^{13} \mathrm{CO}_{3}^{-}$(Figure 4a-c). No leakage of $\mathrm{H}^{13} \mathrm{CO}_{3}^{-}$from these vesicles occurred after addition of $50 \mathrm{mM} \mathrm{NaCl}$. A DMSO solution of the transporters was then added to give ligand-to-lipid ratios of $1 \mathrm{~mol} \%$ for 3 , or $0.1 \mathrm{~mol} \%$ for 4 . These transporters promote $\mathrm{Cl}^{-} / \mathrm{H}^{13} \mathrm{CO}_{3}{ }^{-}$exchange, as confirmed by observation of only the NMR signal for extravesicular $\mathrm{H}^{13} \mathrm{CO}_{3}{ }^{-}$(Figure $4 \mathrm{a} / \mathrm{b}$ ). After addition of $0.5 \mathrm{mM} \mathrm{Mn}^{2+}\left(1: 100 \mathrm{Mn}^{2+}\right.$ / $\mathrm{H}^{13} \mathrm{CO}_{3}{ }^{-}$), this $\mathrm{H}^{13} \mathrm{CO}_{3}{ }^{-}$signal was broadened into the baseline, confirming that all of the intravesicular $\mathrm{H}^{13} \mathrm{CO}_{3}^{-}$ions had been exchanged into the extravesicular milieu (Figure $4 \mathrm{a} / \mathrm{b}$ ). A control experiment confirmed this interpretation (Figure 4c). Thus, after addition of DMSO, the separate signals for intravesicular and extravesicular $\mathrm{H}^{13} \mathrm{CO}_{3}$ remained unchanged. Addition of $\mathrm{Mn}^{2+}$ to this control sample erased the 
extravesicular $\mathrm{H}^{13} \mathrm{CO}_{3}{ }^{-}$signal, whereas the intravesicular $\mathrm{H}^{13} \mathrm{CO}_{3}^{-}$signal remained intact since $\mathrm{Mn}^{2+}$ cannot cross the lipid membrane.
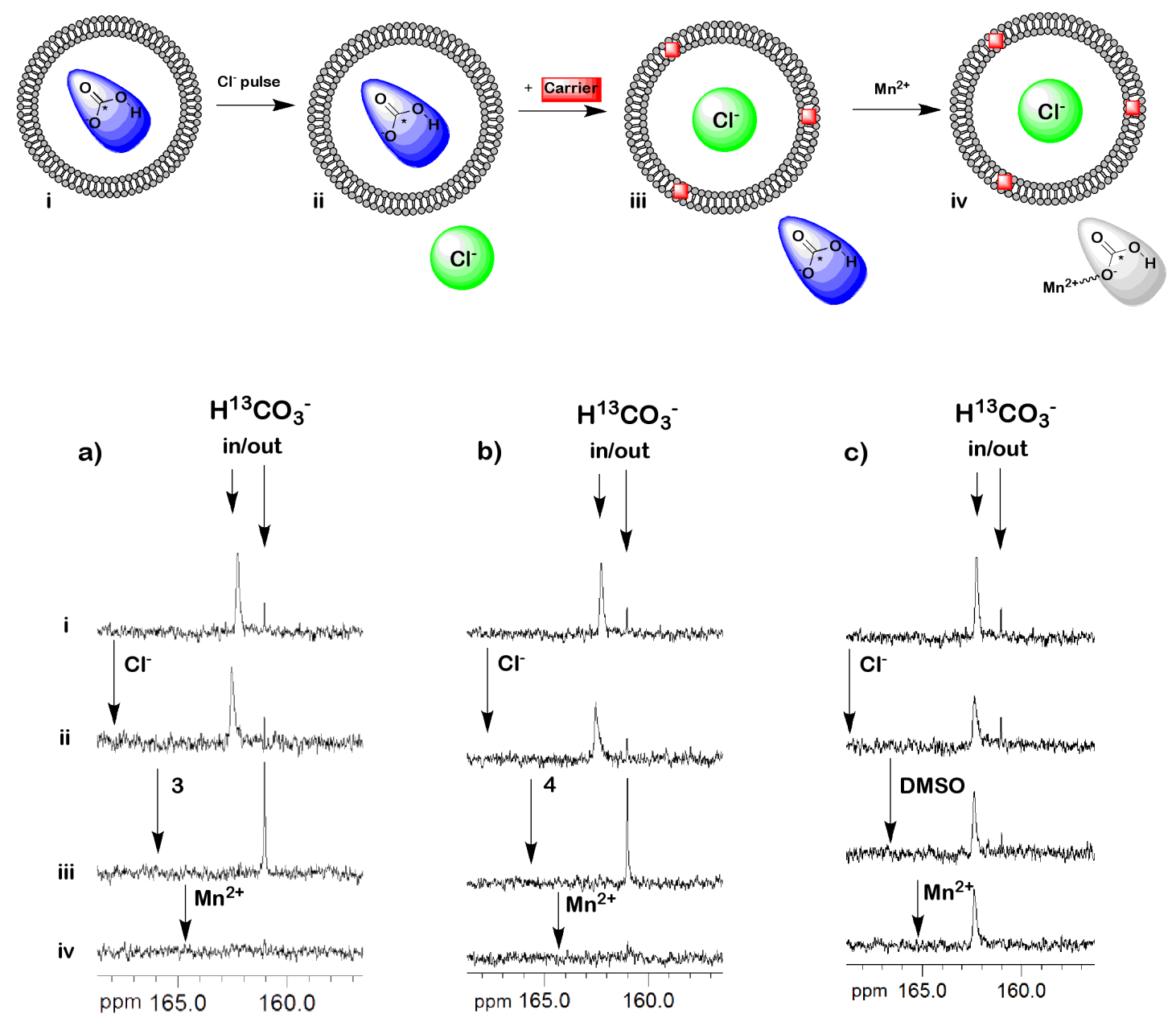

Figure 4. Representation of the titration sequence and NMR stack plots (a-c) for monitoring the transmembrane transport of $\mathrm{HCO}_{3}^{-}$ions in $\mathrm{H}^{13} \mathrm{CO}_{3}^{-}$-loaded EYPC liposomes by 3 and 4 . A $50 \mathrm{mM} \mathrm{NaCl}$ pulse was added to EYPC vesicles loaded with $100 \mathrm{mM} \mathrm{NaH}{ }^{13} \mathrm{CO}_{3}, 20 \mathrm{mM}$ HEPES buffer ( $\mathrm{pH}$ 7.5) and dispersed in $75 \mathrm{mM} \mathrm{Na}_{2} \mathrm{SO}_{4}$, $20 \mathrm{mM}$ HEPES buffer ( $\mathrm{pH} 7.3$ ), and ${ }^{13} \mathrm{C}-\mathrm{NMR}$ data was acquired before (i) and after (ii) the $\mathrm{Cl}^{-}$pulse. NMR spectra were also collected after the addition of transporter or DMSO (3 - $1 \mathrm{~mol} \%, 4-0.1 \mathrm{~mol} \%$, or DMSO - $870 \mathrm{~mol} \%(10 \mu \mathrm{L})$; iii), followed by addition of $0.5 \mathrm{mM} \mathrm{Mn}{ }^{2+}\left(1: 100 \mathrm{Mn}^{2+} / \mathrm{Cl}^{-}\right.$ratio; iv).

\section{DISCUSSION}

This work identifies "small" molecules with activity as transmembrane bicarbonate carriers. The ion selective electrode assays showed that both the synthetic 
isophthalamides 1-3 and the natural product prodigiosin 4 facilitate the release of encapsulated chloride from POPC phospholipid liposomes in the presence of trigonal planar oxoanions such as nitrate and bicarbonate. This efflux is produced via an exchange mechanism with external nitrate anions, in agreement with previous studies. ${ }^{16,29}$ Replacing nitrate by the more hydrophilic sulfate in the external medium resulted in no anion transport activity as an anion exchange mechanism is not possible due to the higher hydrophilicity of the dianionic sulfate. A subsequent assay in which a second anion (bicarbonate) was added to the external sulfate medium showed that chloride transport by compounds 1-4 was restored, clear evidence that these compounds facilitate $\mathrm{HCO}_{3}{ }^{-} / \mathrm{Cl}^{-}$exchange across phospholipid membranes. ${ }^{13} \mathrm{C} \mathrm{NMR}$ assays provided direct evidence for transmembrane bicarbonate transport, as the intraand extra-vesicular carbon-13 labelled bicarbonate populations could be clearly distinguished. This NMR data, when combined with results from the $\mathrm{Cl}^{-}$-selective electrode experiments, firmly establish that compounds 1-4 enable the transmembrane exchange of $\mathrm{Cl}^{-} / \mathrm{HCO}_{3}{ }^{-}$anions.

In conclusion, we have demonstrated for the first time that "small" molecules, including simple synthetic transporters 1-3 and the natural product prodigiosin 4, are able to mimic the natural chloride/bicarbonate exchange process that is typically mediated by membrane proteins. This is the first report that prodigiosin can facilitate chloride/bicarbonate antiport exchange, an important discovery that may present an alternative mechanism by which such compounds affect biological systems. Synthetic bicarbonate/chloride antiporters may also prove to be useful tools for biomembrane research and membrane based processes. Efforts aimed at producing improved and selective bicarbonate transporters and the investigation of their biological activity are currently underway in our laboratories.

\section{METHODS}

Preparation of Phospholipid Vesicles. A chloroform solution of 1-palmitoyl-2oleoyl-sn-glycero-3-phosphocholine (POPC) (20 mg/mL) (Genzyme) was evaporated in vасио using a rotary evaporator and the lipid film obtained was dried under high vacuum for at least 2 hours. The lipid film was rehydrated by addition of a sodium chloride solution ( $488 \mathrm{mM} \mathrm{NaCl}$ and $5 \mathrm{mM}$ phosphate buffer, $\mathrm{pH} 7.2$ or $451 \mathrm{mM}$ $\mathrm{NaCl}$ and $20 \mathrm{mM}$ phosphate buffer, $\mathrm{pH}$ 7.2) and followed by careful vortexing. The lipid suspension was then subjected to nine freeze-thaw cycles and twenty-nine extrusions through a $200 \mathrm{~nm}$ polycarbonate Nucleopore membrane using a LiposoFast Basic extruder (Avestin, Inc.) to obtain unilamellar vesicles. The vesicles were dialyzed against a $\mathrm{NaNO}_{3}$ solution $\left(488 \mathrm{mM} \mathrm{NaNO}_{3}\right.$ and $5 \mathrm{mM}$ phosphate buffer, $\mathrm{pH}$ 7.2) or $\mathrm{Na}_{2} \mathrm{SO}_{4}$ solution ( $150 \mathrm{mM} \mathrm{Na} \mathrm{SO}_{4}$ and $20 \mathrm{mM}$ phosphate buffer, $\mathrm{pH}$ 7.2) to remove unencapsulated $\mathrm{NaCl}$.

ISE Transport Assays. Unilamellar vesicles (200 nm mean diameter) composed of POPC containing an encapsulated solution of $488 \mathrm{mM} \mathrm{NaCl}$ and $5 \mathrm{mM}$ phosphate buffer $\mathrm{pH} 7.2$ or $451 \mathrm{mM} \mathrm{NaCl}$ and $20 \mathrm{mM}$ phosphate buffer $\mathrm{pH} 7.2$, were suspended 
in a solution of $488 \mathrm{mM} \mathrm{NaNO}_{3}$ and $5 \mathrm{mM}$ phosphate buffer $\mathrm{pH} 7.2$, or $150 \mathrm{mM}$ $\mathrm{Na}_{2} \mathrm{SO}_{4}$ and $20 \mathrm{~m} \mathrm{M}$ phosphate buffer $\mathrm{pH}$ 7.2, for a final lipid concentration of $1 \mathrm{mM}$. A DMSO solution of the carrier molecule, typically $10 \mu \mathrm{L}$ to avoid influence of the solvent molecules in the assay, was added and the chloride release from vesicles was monitored using an Accumet chloride selective electrode for 7 minutes. At a time $(\mathrm{t})=$ $5 \mathrm{~min}$ the vesicles were lysed with detergent (polyoxyethylene (8) lauryl ether) to release all chloride ions; the resulting value was considered to represent $100 \%$ release and used as such.

For the anion exchange assays in the vesicles suspended in a $\mathrm{Na}_{2} \mathrm{SO}_{4}$ solution a solution of $\mathrm{NaHCO}_{3}$ or $\mathrm{NaNO}_{3}$ was added for a final concentration of $40 \mathrm{mM}$ at $\mathrm{t}=2$ min. The chloride efflux was monitored for another 5 minutes and at a time $(\mathrm{t})=7$ min the vesicles were lysed with detergent (polyoxyethylene (8) lauryl ether) to release all chloride ions; the resulting value was considered to represent $100 \%$ release and used as such.

\section{${ }^{13}$ C NMR Assays}

Materials. ${ }^{13} \mathrm{C}$ NMR spectra were recorded on a Bruker DRX500 instrument operating at $125.77 \mathrm{MHz}$, with chemical shifts reported in ppm. Egg yolk phosphatidylcholine (EYPC) lipids, nuclepore ${ }^{\circledR}$ polycarbonate membranes and membrane filters were purchased from Avanti Polar Lipids. Deuterated solvents were purchased from Cambridge Isotope Laboratories. Prodigiosin was a gift from the Development Theraputics Program at the National Cancer Institute, U. S. National Institutes of Health. All other chemicals were purchased from Sigma, Aldrich, Fisher, Fluka, or Acros and used without further purification.

Liposome Preparation for ${ }^{13} \mathbf{C}$ NMR Assays. Giant EYPC liposomes $(5 \mu \mathrm{m})$ were prepared by evaporating a chloroform solution of EYPC $(20 \mathrm{mg} / \mathrm{mL})$ under reduced pressure, resulting in a thin film that was dried in vacuo overnight. The liposomes were then formed by rehydrating the lipid film with either $450 \mathrm{mM} \mathrm{NaCl}$ in $20 \mathrm{mM}$ HEPES (pH 7.3) buffer (for the liposomes described in Figure 5 of main text, i.e., the $\mathrm{Cl}^{-}$-loaded liposomes), or $100 \mathrm{mM} \mathrm{NaH}{ }^{13} \mathrm{CO}_{3}$ in $20 \mathrm{mM}$ HEPES (pH 7.5) buffer (for the liposomes described in Figure 4, i.e., the $\mathrm{HCO}_{3}{ }^{-}$-loaded liposomes). Buffer solutions were prepared in a 9:1 $\mathrm{H}_{2} \mathrm{O} / \mathrm{D}_{2} \mathrm{O}$ mixture. After 5 freeze/thaw cycles, the liposomes were extruded through a $5 \mu \mathrm{m}$ polycarbonate membrane 41 times at room temperature using a high-pressure mini-extruder (Avanti). For the $\mathrm{Cl}^{-}$-loaded liposomes, the giant liposome suspension obtained after extrusion was used without further purification in the ${ }^{13} \mathrm{C}$ NMR transport assays. However, for the $\mathrm{HCO}_{3}{ }^{-}$-loaded liposomes, the resulting giant liposome suspension was separated from extravesicular $\mathrm{NaH}^{13} \mathrm{CO}_{3}$ by size exclusion chromatography (SEC) (stationary phase: Sephadex G25, mobile phase: 9:1 $\mathrm{H}_{2} \mathrm{O} / \mathrm{D}_{2} \mathrm{O}, 20 \mathrm{mM}$ HEPES, $\mathrm{pH}$ 7.3, $75 \mathrm{mM} \mathrm{Na}_{2} \mathrm{SO}_{4}$ ). The 30 $\mathrm{mL}$ suspension $\left(\mathrm{NaH}^{13} \mathrm{CO}_{3}\right.$ inside, $\mathrm{Na}_{2} \mathrm{SO}_{4}$ outside) collected was centrifuged (Eppendorf Centrifuge 5804R) at 10,000 rpm for 30 minutes followed by the removal of the non-liposome containing buffer. The recovered giant liposome suspension was then diluted with the $75 \mathrm{mM} \mathrm{Na}_{2} \mathrm{SO}_{4}$ mobile phase buffer and used directly in the ${ }^{13} \mathrm{C}$ 
NMR transport assays. The stock concentrations obtained for the liposomes were 90.3 $\mathrm{mM}$ for the $\mathrm{Cl}^{-}$-loaded liposomes (assuming 100\% lipid retention after extrusion) and $66.6 \mathrm{mM}$ for the $\mathrm{HCO}_{3}{ }^{-}$-loaded liposomes (assuming $80 \%$ lipid retention after gel filtration) respectively.

Bicarbonate Transport in $\mathrm{Cl}^{-}$-Loaded Liposomes Monitored by ${ }^{13} \mathrm{C}$ NMR. ${ }^{13} \mathrm{C}$ NMR spectra were recorded using a Bruker DRX500 spectrometer with a $5 \mathrm{~mm}$ broad band probe operating at $125.77 \mathrm{MHz}$, with chemical shifts reported in ppm. The instrument was locked on 9:1 $\mathrm{H}_{2} \mathrm{O} / \mathrm{D}_{2} \mathrm{O}$. Experimental conditions were: acquisition time, $0.93 \mathrm{~s}$; spectrum width, $35211 \mathrm{~Hz}$; $90^{\circ}$ pulse width, $6.70 \mu \mathrm{s}$; relaxation delay, $0.2 \mathrm{~s}$; number of scans, 160 ; temperature, $27^{\circ} \mathrm{C}$. For each experiment, $230 \mu \mathrm{L}$ of stock $(90.3 \mathrm{mM})$ liposome solution was mixed with $340 \mu \mathrm{L}$ of $150 \mathrm{mM} \mathrm{Na}_{2} \mathrm{SO}_{4}$ in 20 mM HEPES ( $\mathrm{pH}$ 7.3) buffer in a $5 \mathrm{~mm}$ NMR tube to give a liposome suspension containing $\mathrm{NaCl}$ inside, and $\mathrm{Na}_{2} \mathrm{SO}_{4}$ outside. $\mathrm{A} \mathrm{NaH}^{13} \mathrm{CO}_{3}$ pulse was then added to the mixture to give $35 \mathrm{mM}$ and $50 \mathrm{mM}$ final concentrations of liposome and $\mathrm{H}^{13} \mathrm{CO}_{3}{ }^{-}$ respectively. The ${ }^{13} \mathrm{C} \mathrm{NMR}$ of the preceding liposome mixture $\left(\mathrm{NaCl}\right.$ inside, $\mathrm{Na}_{2} \mathrm{SO}_{4}$ and $\mathrm{NaH}^{13} \mathrm{CO}_{3}$ outside) was then taken. After data acquisition, a solution of $\mathrm{MnCl}_{2}$ was added to give a final $\mathrm{Mn}^{2+}$ concentration of $0.5 \mathrm{mM}\left(1: 100 \mathrm{Mn}^{2+} / \mathrm{H}^{13} \mathrm{CO}_{3}{ }^{-}\right.$ratio), and immediately followed by another set of data acquisition. Finally, a final set of ${ }^{13} \mathrm{C}$ NMR data was collected after the addition of a solution of the ligand $(\mathbf{1}, \mathbf{3}$ or $\mathbf{4})$ or DMSO to the mixture. Isophthalamides 1 and $\mathbf{3}$ were added in a 1 mol\% ligand-tolipid ratio, while prodigiosin 4 was added in a $0.1 \mathrm{~mol} \%$ ligand-to-lipid ratio. For the DMSO control, $6 \mu \mathrm{L}$ of the solvent was added corresponding to a $403 \mathrm{~mol} \%$ DMSOto-lipid ratio.

Bicarbonate Transport in $\mathrm{HCO}_{3}^{-}$-Loaded Liposomes Monitored by ${ }^{13} \mathrm{C} \mathrm{NMR}$. Instrument details are the same as described above for the $\mathrm{Cl}^{-}$-loaded liposomes. The instrument was locked on 9:1 $\mathrm{H}_{2} \mathrm{O} / \mathrm{D}_{2} \mathrm{O}$. Experimental conditions were: acquisition time, $0.93 \mathrm{~s}$; spectrum width, $35211 \mathrm{~Hz}$; $90^{\circ}$ pulse width, $6.70 \mu \mathrm{s}$; relaxation delay, $0.2 \mathrm{~s}$; number of scans, 196 ; temperature, $27^{\circ} \mathrm{C}$. For each experiment, an initial ${ }^{13} \mathrm{C}$ $\mathrm{NMR}$ spectrum of $520 \mu \mathrm{L}$ of the giant liposome solution was acquired. Then, a $\mathrm{NaCl}$ pulse resulting in final extravesicular concentrations of $58 \mathrm{mM}$ and $50 \mathrm{mM}$ for the giant liposomes and $\mathrm{Cl}^{-}$respectively was added to the NMR tube. The ${ }^{13} \mathrm{C} \mathrm{NMR}$ of the preceding liposome mixture $\left(\mathrm{NaH}^{13} \mathrm{CO}_{3}\right.$ inside, $\mathrm{Na}_{2} \mathrm{SO}_{4}$ and $\mathrm{NaCl}$ outside) was taken followed by the addition of a solution of the ligand $(\mathbf{1}, \mathbf{3}$ or 4$)$ or DMSO to the cocktail. Again, isophthalamides $\mathbf{1}$ and $\mathbf{3}$ were added in a 1 mol\% ligand-to-lipid ratio, while prodigiosin 4 was added in a 0.1 mol\% ligand-to-lipid ratio. For the DMSO control, $10 \mu \mathrm{L}$ of the solvent was added corresponding to an $870 \mathrm{~mol} \%$ DMSO-to-lipid ratio. A ${ }^{13} \mathrm{C}$ NMR spectrum of the ligand-containing cocktail was then acquired before and after the addition of a solution of $\mathrm{MnCl}_{2}\left(0.5 \mathrm{mM}\right.$ final $\mathrm{Mn}^{2+}$ concentration corresponding to $1: 100 \mathrm{Mn}^{2+} / \mathrm{Cl}^{-}$ratio). 


\section{ACKNOWLEDGMENTS}

J. D. and P. A. G. thank the NSF/EPSRC for funding this research through the "International Collaboration in Chemistry" program under CHE-0822244 and EP/G002576/1. R. Q. thanks the Spanish Ministerio de Educación y Ciencia for support "Jose Castillejo" mobility grant and "Ramon y Cajal" contract. T.T. thanks DGI of Spain (CTQ2006-15456-C04-04BQU) for funding. O.A.O thanks the University of Maryland Graduate School for the Mabel Spencer Fellowship award.

\section{AUTHOR CONTRIBUTIONS}

J.T.D., P.A.G. and R.Q conceived this project, experiments, analyzed data and prepared the manuscript; O.A.O. and R.Q. conducted experiments and analyzed data; P.P. and T.T. contributed reagents, materials, analysis tools and supervised the synthesis; J.C.I.S. and R.Q. synthesized new compounds.

\section{References}

1. Cleland, W. W. et al. Mechanism of Rubisco: The Carbamate as General Base Chem. Rev. 98, 549-561 (1998).

2. Hempling, H.G. Intracellular Water and the Regulation of Cell Volume and $\mathrm{pH}$ in Principles of Medical Biology Eds: Bittar E.E. \& N. Bittar Elsevier 1996.

3. Lipscomb, W. N. \& Strater, N. Recent Advances in Zinc Enzymology. Chem. Rev. 96, 2375-2433 (1996).

4. Florman, H. M., Jungnickel \& M. K.; Sutton, K. A. What can we learn about fertilization from cystic fibrosis? Proc. Nat. Acad. Sci.-USA 104, 11123-11124 (2007).

5. Fujinaga, J., Loiselle, F. B. \& Casey, J. R. Transport activity of chimaeric AE2-AE3 chloride/bicarbonate anion exchange proteins Biochem. J. 371, 687-696 (2003).

6. Choi, J. Y. et al. Aberrant CFTR-dependent $\mathrm{HCO}_{3}{ }^{-}$transport in mutations associated with cystic fibrosis Nature 410, 94-97 (2001).

7. Casey, J. R. Why Bicarbonate? Biochem. Cell Biol. 84, 930-939 (2006)

8. Koropatkin, N. M. et al. The Structure of a Cyanobacterial Bicarbonate Transport Protein, CmpA J. Biol. Chem. 282, 2606-2614 (2007).

9. Davis, A. P., Shepard, D. N. \& Smith, B. D. Development of synthetic membrane transporters for anions Chem. Soc. Rev. 36, 348-357 (2007)

10. Okunola, O. A. et al. Membrane-active calixarenes: toward 'gating' transmembrane anion transport Tetrahedron 63, 10743-10750 (2007).

11. You, L. \& Gokel, G. W. Fluorescent, synthetic amphiphilic heptapeptide anion transporters: Evidence for self-assembly and membrane localization in liposomes Chem. Eur. J. 14, 5861-5870 (2008).

12. Izzo, I. et al. Cationic calix[4]arenes as anion-selective ionophores Chem. Commun. 2986-2988 (2008). 
13. Whitmarsh, S.D. et al. Cationic cyclocholamides; toroidal facial amphiphiles with potential for anion transport Chem. Commun. 3669-3671 (2008).

14. Gale, P.A. et al. Co-transport of $\mathrm{H}+/ \mathrm{Cl}-$ by a synthetic prodigiosin mimic, Chem. Commun. 3773-3775 (2005).

15. Gale, P. A. et al. Conformational control of $\mathrm{HCl}$ co-transport: imidazole functionalised isophthalamide vs. 2,6-dicarboxamidopyridine Chem. Commun. 1736-1738 (2007).

16. Santacroce, P. V. et al. Conformational Control of Transmembrane $\mathrm{Cl}^{-}$ Transport J. Am. Chem. Soc. 129, 1886-1887 (2007).

17. Kavallieratos, K.; Bertao, C.M. \& Crabtree R.H. Hydrogen bonding in anion recognition: A family of versatile, non-preorganized neutral and acyclic receptors J. Org. Chem. 64, 1675-1683 (1999).

18. Fürstner, A. Chemistry and biology of roseophilin and the prodigiosin alkaloids: A survey of the last 2500 years Angew. Chem., Int. Ed., 42, 3582-3603 (2003).

19. Gerber, N.N. Prodigiosin-like pigments Crit. Rev. Microbiol. 3, 469-485 (1975).

20. Bennett, J.W. \& Bentley R. Seeing red: The story of prodigiosin Adv. Appl. Microbiol. 47, 1-32 (2000).

21. Williamson, N.R. et al. Anticancer and immunosuppressive properties of bacterial prodiginines, Future Microbiol., 2, 605-618 (2007).

22. Nguyen, M. et al. Small molecule obatoclax (GX15-070) antagonizes MCL-1 and overcomes MCL-1-mediated resistance to apoptosis, Proc. Natl. Acad. Sci. U. S. A., 104, 19512-19517 (2007).

23. Yamamoto, C. et al. Cycloprodigiosin hydrochloride, a new $\mathrm{H}^{+} / \mathrm{Cl}^{-}$ symporter, induces apoptosis in human and rat hepatocellular cancer cell lines in vitro and inhibits the growth of hepatocellular carcinoma xenografts in nude mice Hepatology 30, 894-902 (1999).

24. Tanigaki, K. et al. BE-18591 as a new $\mathrm{H}^{+} / \mathrm{Cl}^{-}$symport ionophore that inhibits immunoproliferation and gastritis FEBS Lett. 524, 37-42 (2002).

25. T. Sato, et al., Prodigiosins as a New Group of $\mathrm{H}^{+} / \mathrm{Cl}^{-}$Symporters That Uncouple Proton Translocators J. Biol. Chem., 273, 21455-21462 (1998).

26. Gottlieb, R.A. et al. Apoptosis induced in Jurkat cells by several agents is preceded by intracellular acidification, Proc. Natl. Acad. Sci. U.S.A. 93, 654-658 (1996).

27. S. Ohkuma, et al. Prodigiosins uncouple vacuolar-type ATPase through $\mathrm{H}^{+} / \mathrm{Cl}^{-}$symport Biochem. J. 334, 731-741 (1998).

28. Sessler, J.L. et al. Synthesis, anion-binding properties, and in vitro anticancer activity of prodigiosin analogues, Angew. Chem. Int. Ed. 44, 5989-5992 (2005).

29. Seganish, J.L. \& Davis, J.T. Prodigiosin is a chloride carrier that can function as an anion exchanger, Chem. Commun., 5781-5783 (2005). 
30. Diaz, R.I.S. et al. Chloride anion transport and copper-mediated DNA cleavage by C-ring functionalized prodigiosenes, Chem. Commun. 27012703 (2007).

31. Koulov, A.V. et al. Chloride transport across vesicle and cell membranes by steroid-based receptors, Angew. Chem. Int. Ed. 42, 4931-4933 (2003).

32. Hofmeister, F. Zur Lehre von der Wirkung der Salze, Zweite Mittheilung, Arch. Exp. Pathol. Pharmakol. 24, 247-260 (1888).

33. Steinle, E.D., Schaller, U. \& Meyerhoff, M.E. Response Characteristics of Anion-Selective Polymer membrane Electrodes Based on Gallium(III), Indium(III) and Thallium(III) Porphyrins, Anal. Sciences, 14, 79-84 (1998).

34. Riddell, F.G. et al. Chloride transport through model biological membranes studied by ${ }^{35} \mathrm{Cl}$ NMR, Chem. Commun. 74-76 (1990).

35. Riddell, F.G. \& Zhou, Z. $\mathrm{Mn}^{2+}$ as a contrast reagent for NMR studies of ${ }^{35} \mathrm{Cl}^{-}$and ${ }^{81} \mathrm{Br}^{-}$transport through model biological membranes, J. Inorg. Biochem. 55, 279-293 (1994).

36. Gout, E. et al ${ }^{13} \mathrm{C}$ nuclear magnetic resonance studies of malate and citrate synthesis and compartmentation in higher plant cells, ${ }^{81} \mathrm{Br}^{-}$transport through model biological membranes, J. Biol. Chem. 268, 3986-3992 (1993).

37. Chang, K. \& Roberts, J.K.M. Quantitation of rates of transport, metabolic fluxes, and cytoplasmic levels of inorganic carbon in maize root tips during $\mathrm{K}^{+}$ion uptake, Plant Physiol. 99, 291-297 (1992). 